\title{
Modelling Powder Compaction ${ }^{\dagger}$
}

\author{
Dr. I.C. Sinka \\ Department of Engineering, University of Leicester ${ }^{1}$
}

\begin{abstract}
Die compaction of powders is a process which involves filling a die with powder, compression of the powder using rigid punches to form a dense compact, and ejection from the die. The choice of powder composition and selection of process parameters determine the microstructure and final properties of the compacts. The practical issues in the powder-forming industries (powder metallurgy, ceramics, hard metals, pharmaceuticals, detergents, etc.) are related to mechanical strength, control of microstructure, avoidance of cracks and defects, content uniformity, etc.

We review the modelling strategies used for powder compaction. The main focus is on the constitutive model development for finite element analysis. Knowledge of the following input factors is required:

1. constitutive equations which describe the deformation of a volume of powder under the loads applied during compaction

2. friction interaction between powder and tooling

3. geometry of die and punches

4. pressing schedule, e.g. sequence of punch motions

5. initial conditions that relate to the state of the powder in the die after die fill

The constitutive model and friction relate to fundamental properties of the material and are reviewed in more detail. The methodologies used for model calibration are also described. The remaining factors (geometry, pressing schedule and initial conditions) are specific to particular problems. Their relative effect is discussed by presenting examples for a range of powder materials. We show how compact microstructure can be manipulated by changing the factors discussed above and illustrate the effect of microstructure on final properties. The model predictions are validated using experimental data. The use of numerical analysis in powder formulation design and optimisation of the process parameters is discussed.
\end{abstract}

Keywords: Compaction, Constitutive model, Friction, Modelling

\section{Introduction}

A wide range of engineering components is manufactured using the powder route. Die compaction of powders followed by sintering is used in powder metallurgy, industrial ceramics and the hard metal sectors. Pharmaceutical tablets and detergents are also made from powders using compaction. Thus die

Accepted: August 8, 2007

1 University Road, Leicester, LE1 7RH, UK

TEL: +44 1162522555 , FAX: +44 1162522525

E-mail: ics4@le.ac.uk compaction is a common operation across a range of industries. The process involves filling a powder formulation into a die, compression using rigid punches, and ejection from the die. Post-compaction operations such as sizing, sintering, coating, etc. are usually also applied depending on the application.

In this review we focus on modelling die compaction. In Section 2, we introduce the manufacturing operation and describe characteristics of the process that are common across materials and industries. Product requirements and process-specific issues are discussed for various applications. The modelling approaches are reviewed in Section 3 with focus on 
continatim methods. Section 4 expands on the constitutive models used for powder compaction. The modwels are presented with reference to the experimental procedures used for calibration. The presentation focuses on the structure of the constitutive models rather than on computational aspects. The friction behaviour between powder and die wall during compaction is reviewed in Section 5.

A series of examples is presented in Section 6, highlighting how modelling could help in tackling the practical problems incurred in powder compaction. Experimental results are presented for model validation purposes. The concluding section discusses the current uses of compaction models and future challenges in this field.

\section{Practical Aspects and Issues in Powder Compaction}

In broad terms, compaction machinery can be divided into two categories: single-station and rotary presses. Single-station presses are typically used in powder metallurgy for manufacturing components that are relatively large, have a complex geometry and require high compression forces. Essentially, the process consists of 4 steps: die fill, transfer, compaction and ejection. The transfer stage is introduced so that after die fill, the powder is transferred at a constant volume into a shape that is proportional with the compressed part. The transfer stage is necessary to avoid crack formation. The sequence of punch motion is carefully selected as cracking can occur during each of the 4 stages.

The compressed parts (also referred to as green parts) require a high density in order to achieve the required specifications in terms of strength and dimensional tolerances after sintering. The density distribution in green parts must be kept at a minimum in order to avoid distortions during sintering. Structural ceramics and hard metal components are also subject to similar requirements. Ceramic parts in the green state usually have low strength and can present handling difficulties. The control of tolerances is particularly important for hard metals which are expensive to machine after sintering.

Rotary presses are used for smaller parts with a relatively simple geometry. Rotary presses are used for high-volume production that can exceed 1 million units/hour for pharmaceutical tablets. Powder transfer does not exist as a distinct stage on rotary presses. However, more modern presses allow some degree of powder transfer between die fill and com- paction. Rotary presses require powder handling processes to prevent segregation and robust die fill to ensure weight uniformity.

The practical issues related to density distribution, cracking, dimensional tolerances, and consistency are common across the applications. The compaction process can be analysed in terms of 2 main contributing factors: powder formulation and process parameters. Numerical modelling can be used to optimise the composition of the powder blend (i.e. selection of powder constituents that offer the required constitutive response during compaction) and the selection of process parameters, so that the product, the process and the tooling are designed on a rational basis instead of trial and error which is still widely (and often exclusively) used in powder forming industries at this point in time.

\section{Modelling Approaches for Powder Compaction}

Powder compaction can be described as a large irrecoverable deformation during which the material is transformed from a powder state into a dense compact. This process can be modelled using two main approaches:

1. discrete method, where the behaviour and interaction of individual particles are considered

2. continuum method, where the powder is regarded as a mechanical continuum

The two approaches are reviewed below.

\subsection{Discrete element models}

The discrete element method (DEM) was proposed by Cundall (Cundall and Strack, 1979) for rock and soil mechanics problems. The DEM solves the equations of motion of particles taking into account the interactions between particles in contact. The method has been used to analyse granular flow (Oda and Iwashita, 1999; Landry et al., 2003; Bagi, 1993; Tsuji et al., 1993; Tzaferopoulos, 1996; Tuzun and Heyes, 1997; Thornton and Antony, 2000; Oda and Iwashita, 2000; Thornton and Zhang, 2003). Most DEM studies treat regular particles for which wellestablished interaction laws exist. Irregular particles were also considered (Mirghasemi et al., 2002). The application of DEM has been extended to model die fill (Wu and Cocks, 2006) and powder transfer (Wu et al., 2003).

More recently, the method was also used to model the early stages of powder compaction (Kong and Lannutti, 2000; Heyliger and McMeeking, 2001; Re- 
danzand FPeck 2001). Martin et al. (2003) showed thet DER results were consistent with micromechanical models (described in Section 4.2) for isostatic loading (which assume affine motion of the particles), but with differences occurring as the shear strain is increased. More material-specific applications included metallic powders (DeLo et al., 1999), detergents (Samimi et al., 2005), magnetic materials (Kitahara et al., 2000) and pharmaceutical powders (Hassanpour and Ghadiri, 2004).

DEM, however, normally uses a simplified contact interaction. For detailed contact laws and incorporation of arbitrary material properties for the particles, the response of individual particles was modelled using the finite element method (Ransing et al., 2000, Lewis et al., 2005). This treatment was termed "multiparticle finite element model” (MPFEM) by Procopio at Zavaliangos (2005), and could be used near full density. Similar to the DEM simulations of Redanz and Fleck (2001), the MPFEM was used to investigate the effect of friction between particles on the macroscopic yield response of the aggregates. Common features with the micromechanical models and continuum models were identified.

\subsection{Continuum models}

The powder material can also be regarded as a mechanical continuum. This assumption is considered valid if the size of the powder particles is several orders of magnitude smaller than the size of the die or final compact. Thus representative volumes of sufficiently large numbers of particles can be defined which adequately represent the macroscopic behaviour of the material. Using this approach, the details of the motion, deformation and interaction of a particle with its environment are all included in macroscopic constitutive laws. Within the continuum mechanics framework, powder compaction can be modelled similarly as a large deformation plasticity problem. Such a problem lends itself to specific methods such as finite element analysis, which is used to solve the balance laws (conservation of mass, momentum and energy) and constitutive laws (stressstrain and friction laws). For powder compaction, knowledge of the following factors is necessary:

1. constitutive law, which describes the deformation of a volume of powder under the loads applied during compaction

2. friction interaction between powder and tooling

3. geometry of die and punches

4. pressing schedule, i.e. sequence of punch motions
5. initial conditions that relate to the state of the powder in the die after die fill

The constitutive model and friction are fundamental ingredients that require detailed characterisation and formulation, and are discussed in Sections 4 and 5 , respectively. The geometry and pressing schedule are process-specific parameters which depend on the application. The initial condition of the powder in the die is the final outcome of the die fill process that precedes compaction. The details of the die fill process have been studied extensively by Cocks and coworkers (e.g. Wu and Cocks, 2006) and are outside the scope of the current review.

Once the problem is formulated in terms of the 5 factors above, the finite element method can be used to predict the compact microstructure and calculate the tool loading and deformation. Sensitivity studies of all intervening factors and material parameters can be carried out. Finite element modelling results can be used to optimise the formulation of the powder and the selection of process parameters for a given performance criterion. This approach is general for all classes of powders and can be used in formulation design and process development across the powderforming industries.

\section{Constitutive Models for Powder Compaction}

\subsection{Phenomenological models}

The fundamental aspects of the mechanics of powder compaction from a constitutive modelling point of view have been discussed by Cooks (2007).

Review papers on constitutive models for metallic, ceramic and pharmaceutical powders have been presented in the literature (Trasorras et al., 1998; Aydin et al., 1997; Cunningham et al. 2004; Kremer and Hancock, 2006). Early empirical models assume quadratic yield surfaces (Shima and Oyane, 1976; Kuhn and Downey, 1973) where the state of the material is described using density. These models were developed using data for sintered materials and assume the same strength in tension and compression for the compact. Experiments (Brown and Weber, 1998) have shown, however, that the properties of green compacts are considerably different.

At the two ends of the density spectrum (or low and high porosity), the behaviour of powders can be described as similar to that of soils and mildly voided metals, respectively. The models developed for these applications are discussed below.

The model introduced by Gurson (1977) on the micromechanical principles for void nucleation 
abid growth during plastic failure was modified by Tvergaard (1981) and became known as the porous W plasticity model. This model is also symmetric with respect to the origin, and therefore predicts the same strength in tension and compression. To overcome these difficulties, constitutive models developed in the field of rock and soil mechanics such as the Cam Clay (Schoefield and Wroth, 1968), Drucker-Prager cap (Drucker and Prager, 1952) or the model proposed by Di-Maggio and Sandler (1971) have also been adapted to model powder compaction.

The experimental methods for model calibration are also derived from the soil mechanics literature. The methods are discussed alongside the DruckerPrager cap model as this is a phenomenological model which makes use of well-known material parameters such as cohesion and the internal friction angle. The yield surface is described by a shear failure line and a compaction surface, as illustrated in Fig. $\mathbf{1}$ in the effective stress $\left(\sigma_{e}\right)$ and hydrostatic stress $\left(\sigma_{m}\right)$ space. The shear failure line is defined by cohesion $(c)$ and the internal friction angle $(\beta)$, which are determined using simple tests such as uniaxial tension and compression, simple shear and diametrical compression. Triaxial tests, where a cylindrical sample is subject to a confining pressure and superimposed axial load, can be used to characterise the failure line for hydrostatic stress states that are greater than during uniaxial compression. Triaxial testing also originated from rock and soil mechanics and has been used to determine the flow (Eelkman
Rooda and Haaker, 1977) and compaction properties (Doremus et al., 1995; Shima et al., 1997; Akisanya et al., 1997; Kamath and Puri, 1997; Sinka et al., 2000; Zeuch et al., 2001; Schneider and Cocks, 2002; Lee and Kim, 2007) of a wide range of powder materials.

The compaction (cap) surface is described using an ellipse which is determined by 2 parameters and therefore requires 2 points in stress space, which can be obtained using various types of triaxial tests as illustrated in Fig. 1. A more pragmatic approach (exemplified in Section 6.1) is represented by the use of a die with radial stress measurement capability. However, in this case the response of the powder also includes the effect of friction between powder and die wall.

The Cam-Clay and Drucker-Prager cap models became widely adopted. Comparative studies from 5 research centres (PM Modnet Computer Modelling Group, 2002; Cocks et al. 2007) on modelling the compaction of the same multilevel part were benchmarked against experimental data from a press (Kergadallan et al., 1997). These efforts highlighted the sensitivity of the output with respect to friction, fill density and constitutive models. The predictions in terms of density distributions were broadly consistent across the case studies. This is not surprising: Fig. 1b illustrates yield surfaces for 3 models (porous plasticity, Cam-Clay and Drucker-Prager cap) calibrated using the same set of closed-die compaction data. In the vicinity of the closed-die compaction point, the models are almost identical, therefore the
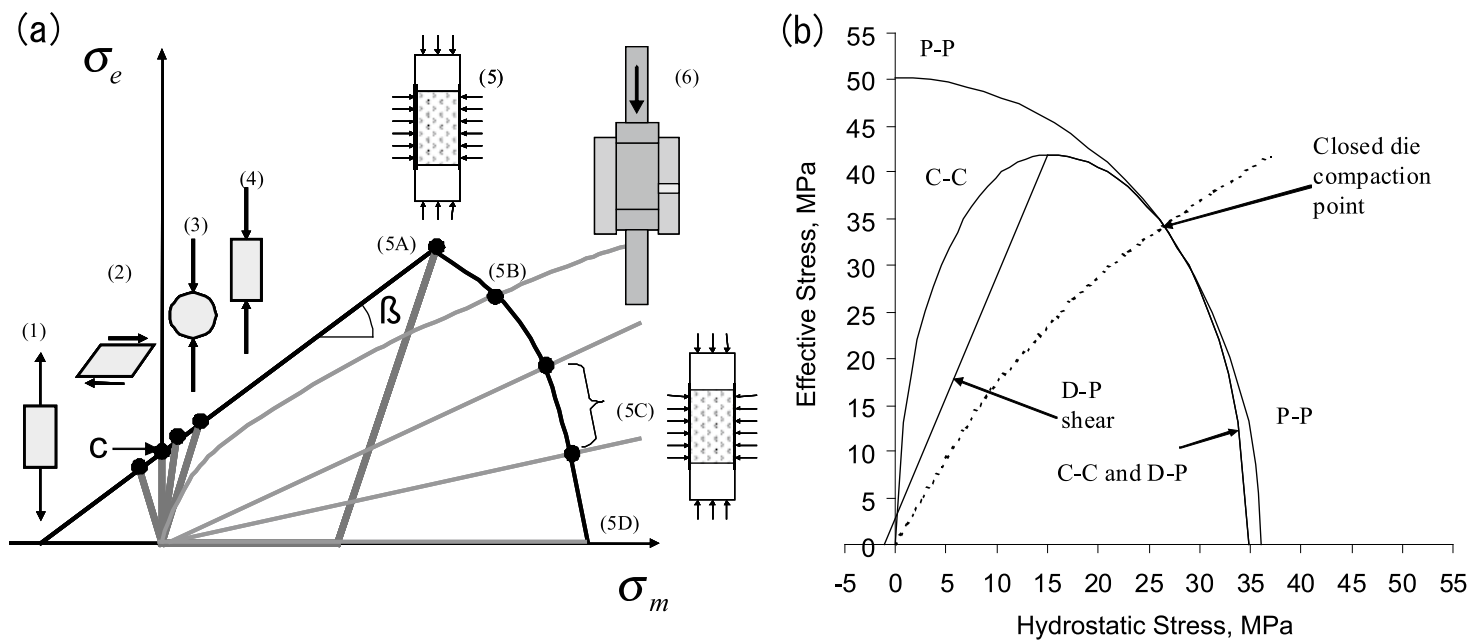

Fig. 1 Constitutive models for powder compaction, a) experimental procedures for determining Drucker-Prager cap model parameters. Failure line: (1) uniaxial tension, (2) simple shear, (3) diametrical compression, (4) uniaxial compression. Compaction surface: (5) triaxial testing: $5 \mathrm{~A}$ consolidated triaxial test, 5B simulated closed-die compaction, 5C radial loading in stress space, 5D isostatic test; (6) instrumented die compaction. b) Yield surfaces for microcrystalline cellulose using various models calibrated on a closed-die compaction experiment: C-C Cam-Clay, D-P Drucker-Prager cap, P-P porous plasticity. The closed-die compaction trajectory is indicated with a dotted line. 
prediations. Would be similar. Differences however, weuld be obtained for high shear stress states, i.e. around the transition corners in multilevel parts.

The models developed for soil behaviour have been modified over the years in terms of the shape of the shear failure line, the shape of the cap surface and the flow rule. $3 \mathrm{D}$ simulations of the compaction of complex parts (Coube and Riedel, 2000; Khoei et al., 2007) are becoming common.

In the models above, density is used almost exclusively as the state variable. The main reason is that metal powder component manufacturers are interested in high density (to maximise mechanical performance) and low density variations in the green parts. However, triaxial test results on metallic powders, hard metals and ceramics (Sinka et al., 2001) suggest that density may not be the most appropriate state variable to describe the compaction response of powders. It is therefore instructive to critically examine the structure of the constitutive models in order to identify a simple, single state variable model that is able to describe the material response when subject to loading paths similar to those encountered in industrial practice. An appropriate basis for evaluating the structure of constitutive models for compaction is represented by micromechanical models which are reviewed below.

\subsection{Micromechanical models}

The micromechanical model developed by Fleck et al. (1992) uses the upper bound plasticity theorem to determine the macroscopic response (i.e. yield surface) of a random array of particles. The particles are assumed to be rigid-plastic spheres. The contact between particles is frictionless and the contact strength in tension and compression is considered equal. Although the assumptions used in the micromechanical model greatly simplify the geometry and material properties of real powders, it is shown in Section 4.3 that the resulting models produce similar features to the compaction and failure surfaces of the Drucker-Prager cap model.

Early micromechanical models predict similar yield strength in tension and compression. By relaxing the underlying assumptions (Fleck, 1995), Fleck demonstrated that yield surfaces depend on the loading history, which cannot be captured by a single state variable such as density. The models were further developed to include other contact laws and different particle sizes and properties (Fleck et al., 1997). Yield surfaces predicted for isostatic, closeddie and pure shear deformation are presented in Fig.

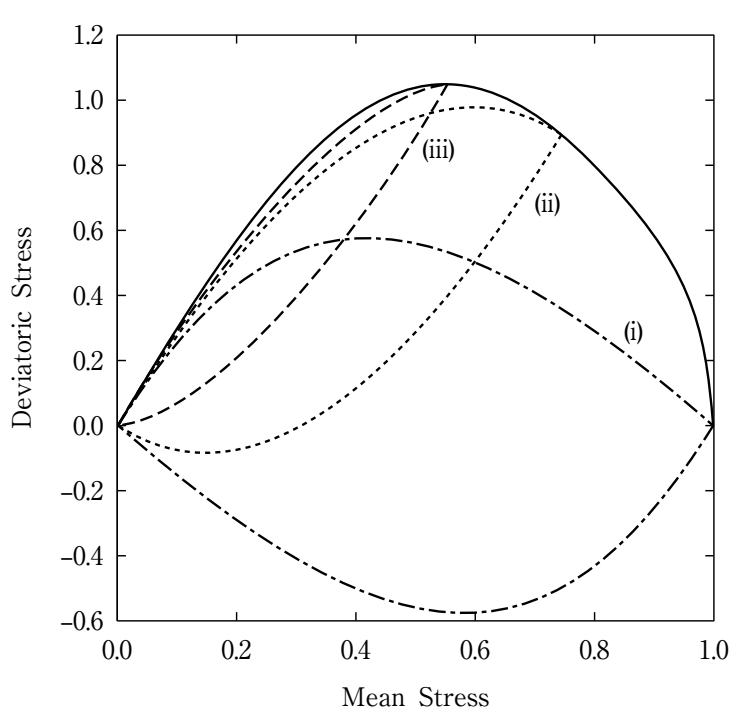

Fig. 2 Normalised surface of constant complementary work predicted by micromechanical models and yield surfaces for (i) isostatic compaction, (ii) frictionless closed-die compaction and (iii) pure shear deformation. This figure was published in Mechanics of Materials, Vol. 39, Cocks A.C.F. and Sinka I.C., Constitutive Modelling of Powder Compaction - I. Theoretical Concepts, 392-403, Copyright Elsevier (2007).

2. The micromechanical model predictions were in broad agreement with the yield surfaces obtained by triaxial tests on monosized spherical copper particles (Akisanya et al., 1997; Schneider and Cocks, 2002). As illustrated in Fig. 2, micromechanical models suggest that for monotonically increasing loading paths, the yield surfaces present a vertex at the loading point. This is an important feature of the micromechanical models which have been used to develop alternative approaches for powder compaction as described in the following section.

\subsection{Deformation theory for powder compaction}

All models described above are developed using the incremental plasticity framework, which is based on the existence of a yield surface and a flow rule. The empirical models described in Section 4.1 assume prescribed yield surfaces (i.e. the DruckerPrager cap model) which are not critically assessed and the experiments used to determine the material properties are not normally representative of the stress histories that occur in practice. The micromechanical models described in Section 4.2 are based on limiting assumptions. Indeed, for irregularly shaped powders, the yield surfaces determined experimentally can have completely different shapes (Schneider and Cocks, 2002). Also, yield surfaces presenting vertices present numerical difficulties.

Cocks and co-workers (Cocks, 2001; Cocks and 
The micromechanical models were re-examined to consider an observation of Budiansky (1959) that for situations where the yield surfaces present vertices, the material response is not too sensitive to the loading path followed to achieve the terminal state. For such loading histories, it is appropriate to consider a deformation plasticity model. Using the extremum theorems of Ponter and Martin (Ponter and Martin, 1972), the material behaviour was described using a potential function expressed in terms of Kirchhoff stress. The strains can then be determined by differentiating the potential with respect to stress.

A normalised surface of constant complementary work predicted by the micromechanical models is presented in Fig. 2. This surface forms an envelope of the actual yield surfaces obtained along radial loading paths to the same terminal state. The theoretical framework for the deformation is presented elsewhere (Cocks and Sinka, 2007).

Triaxial tests were conducted to validate the model for commercial metal powders (Sinka and Cocks, 2007a). Fig. 3 illustrates that it was possible to construct a consistent set of contours of constant complementary work done along radial loading paths in stress space. The underlying assumptions of the

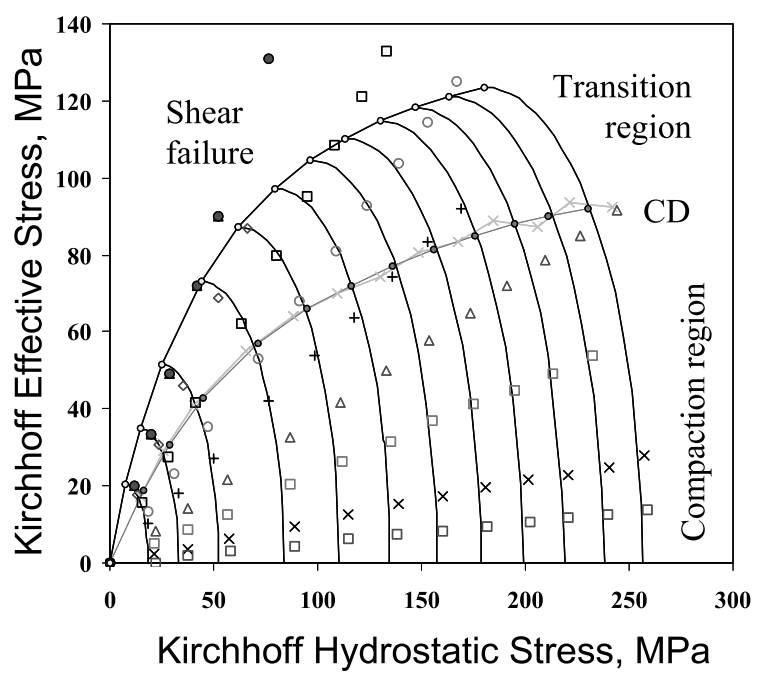

Fig. 3 Contours of constant complementary work done $\left(\mathrm{MJm}^{-3}\right)$ per unit initial volume in Kirchhoff stress space. The data points represent stress states along radial loading paths in stress space and closed-die compaction, labelled CD. This figure was published in Mechanics of Materials, Vol. 39, Sinka I.C. and Cocks A.C.F., Constitutive Modelling of Powder Compaction - II. Evaluation of Material Data, 404-416, Copyright Elsevier (2007).

deformation plasticity model (path independence, normality) have also been verified experimentally. The detailed form of the constitutive model was developed (Sinka and Cocks, 2007a) to satisfy appropriate limit conditions when the material approaches full density. Triaxial tests for hard metals and ceramic powders (Sinka et al., 2001) suggested that the approach can be used for a wider range of materials. It is interesting to note that the shape of the potential surfaces in Fig. 3 is very similar to the DruckerPrager yield surfaces made of a shear failure line and a cap.

The simplicity of the deformation plasticity model allows practical die compaction processes to be analysed efficiently. However, the model does not capture the material response during unloading, ejection and post-compaction operations, which require detailed knowledge of the actual yield surfaces. To model unloading and ejection, it is necessary to change to an incremental plasticity framework in which the form of the yield surface at the end of compaction is determined from the plastic state determined from the deformation plasticity model (Sinka and Cocks, 2007b).

\section{Friction Between Powder and Tooling}

The friction interaction between powder and die wall plays an essential role in powder compaction because it leads to density variations, increased compression and ejection forces and die wear. In industrial practice, friction is reduced by admixing a lubricant to the powder blend or by pre-lubricating the die wall (i.e. by depositing a lubricant onto the die wall before die fill).

Friction is described by Coulomb's law, and a wide range of devices have been developed to characterise friction for various engineering applications. For powder pressing, two types of apparatus have gained acceptance: sliding piece-type devices and instrumented dies. Pavier and Doremus (1997) found that the coefficient of friction was 1.5 times higher when measured using an instrumented die than when determined using the sliding piece test. It was therefore accepted that the friction coefficient should be measured under conditions similar to those encountered during the process under investigation, i.e. die compaction.

For die compaction, dies instrumented with radial stress measuring devices have been developed (Ernst and Barnekow 1994; Pavier and Doremus, 1997; Mosbah et al., 1997). In this configuration, a cylindrical powder specimen is pressed such that one 
of thenunches is stationary. As friction opposes the siveling:of the powder with respect to the die wall, the stress applied by the moving punch is larger than the stress applied by the stationary punch. The friction coefficient can be calculated from the axial stresses and the radial stress transmitted to the die wall (or contact pressure) using the method of differential slices attributed to Janssen in 1895 (Nedderman, 1992), which was developed for hopper and bunker design.

Constitutive models for friction can also be developed from first principles such as plasticity theory (Gearing et al., 2001), contact mechanics approaches or empirical studies (Adams et al., 1987). These models may be complex and/or restricted for certain densification or powder flow regimes.

Experimental studies indicate that friction depends on several factors including: contact pressure, local powder density, sliding velocity, sliding distance, temperature, and wall roughness. (Pavier and Doremus, 1997; Mallender et al., 1974; Ernst and Barnekow 1994; Mosbah et al., 1997; Wikman et al., 1997; Roure et al., 1999). In Section 6.2, we adopt the instrumented die method and present a number of case studies below where the friction coefficient is dependent on contact pressure and die wall condition.

\section{Applications}

In the preceding sections, we have reviewed a number of approaches that can be used for modelling powder compaction. The methodologies are general, i.e. are applicable to a wide range of powder materials such as metallic powders, ceramics, hard metals, magnets, detergents, pharmaceuticals, etc. For example, the discrete element approach captures particle rearrangement, inter-particle friction and allows complex contact laws to be implemented. Similarly, the continuum models are not dependent on the details of the compaction mechanisms of the particles (e.g. plastic flow at the contacts, particle rearrangement and particle breakage are not relevant when calibrating empirical models).

The micromechanical approach is based on the contact law between rigid-plastic spheres, where densification occurs by plastic deformation at the contacts between particles. This behaviour is characteristic to metallic powders; nevertheless, the methodology can be extended to brittle materials. More importantly, however, micromechanical models can present a framework for developing new constitutive theories (i.e. deformation plasticity) which can be generalised to suit any powder system.

In Sections 6.3-6.6, we present examples to illustrate the use of numerical models for powder compaction. A pragmatic calibration procedure for the constitutive law and friction is described in Sections 6.1-6.2 for a pharmaceutical powder. Examples 1 and 2 focus on the density distribution in simple and complex pharmaceutical tablets and illustrate generic issues that are relevant across other powder pressing industries. It is important that model predictions are validated; supporting experimental data are therefore presented when discussing modelling results.

Example 3 illustrates the use of the deformation plasticity model for two ceramic materials, while Example 4 discusses issues related to crack development in pharmaceutical tablets and multilevel metal powder components.

\subsection{Experimental data for constitutive model calibration}

The powder material used in Examples 1 and 2 is microcrystalline cellulose (Avicel PH102 manufactured by FMC Biopolymer), which is commonly used in pharmaceutical tablet formulation. The powder is made of irregular porous particles. The bulk density of the powders is around $300 \mathrm{kgm}^{-3}$, while the full density is $1520 \mathrm{kgm}^{-3}$. The average particle size is $100 \mu \mathrm{m}$.

We adopt a modified Drucker-Prager cap model where the elastic and plastic model parameters are expressed as functions of relative density. The general methodologies for determining the parameters of the model are well established (see Section 4.1). Below, we use a pragmatic method based on data generated using a die instrumented with radial stress sensors. A detailed description of the experimental procedures is given elsewhere (Sinka et al., 2003). The instrumented die approach has been adopted in industrial practice as a simple and efficient way to characterise both constitutive response and friction.

The elastic and plastic model parameters are presented in Fig. 4. Assuming isotropic linear elasticity, Young's modulus and Poisson's ratio can be determined from the unloading curve after the material is compressed to a given density. In order to minimise the effect of friction on the constitutive response, the die was pre-lubricated before each compaction experiment. The evolution of Young's modulus and Poisson's ratio as a function of relative density are given in Fig.s $\mathbf{4 a}$ and $\mathbf{4 b}$.

The Drucker-Prager cap model is composed of a shear failure line and a cap surface as described in Section 4.1. The shear failure line is characterised 


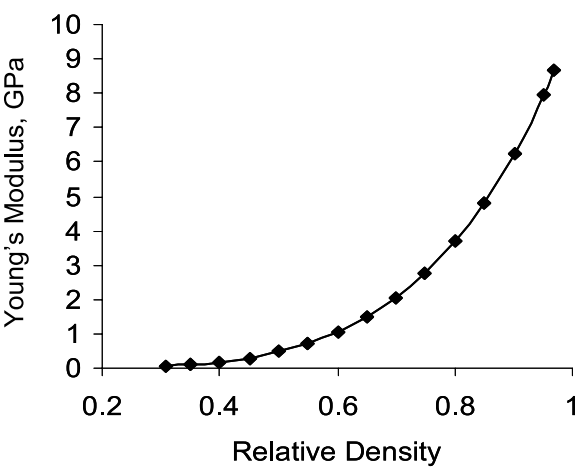

(c)

(b)
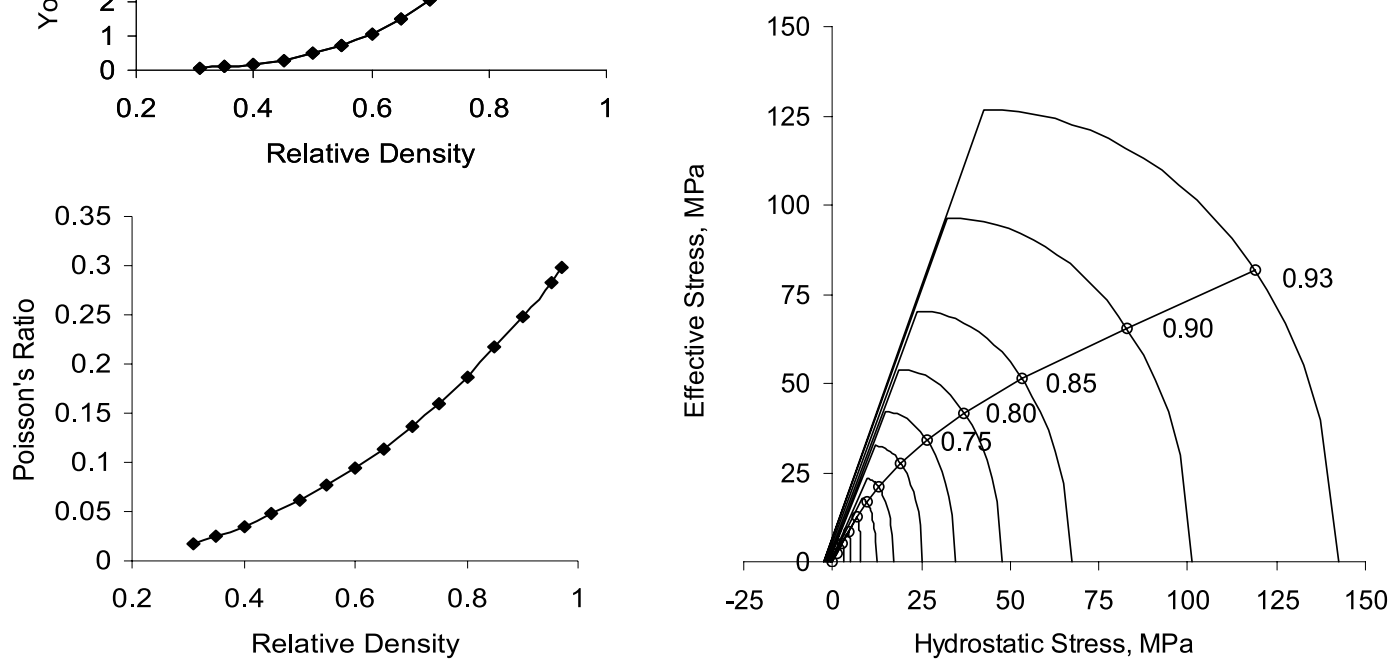

Fig. 4 Constitutive model data for microcrystalline cellulose using relative density as a state variable; a) Young's modulus, b) Poisson's ratio, c) families of Drucker-Prager yield surfaces. The labels indicate relative density. This figure was published in Powder Technology, Vol. 133, Sinka I.C., Cunningham J.C. and Zavaliangos A., The effect of wall friction in the compaction of pharmaceutical tablets with curved faces: A validation study of the Drucker-Prager Cap model, 33-43, Copyright Elsevier (2003).

by cohesion and the internal friction angle, and can be determined using a number of simple tests, as illustrated in Fig. 1a. We use diametrical compression and uniaxial compression of cylindrical compacts.

The cap surface is described by an ellipse which is also characterised by two parameters, the size and shape. During compaction in an instrumented die, the stress state (axial and radial stresses) and the strain increment direction (zero radial strain) at the loading point are known. The parameters of the cap surface are determined using the normality rule. Families of Drucker-Prager cap surfaces with increasing relative density are presented in Fig. $\mathbf{4 c}$, which illustrates the evolution of the size and shape of yield surfaces during densification. The stress path corresponding to closed-die compaction is also indicated in Fig. 4c.

\subsection{Experimental data for friction between pow- der and die wall}

The friction coefficient between powder and die wall is also measured using a die instrumented with radial stress sensors. The friction coefficient was calculated using the method of differential slices (see Section 5). For microcrystalline cellulose, it was found that the friction coefficient was dependent on contact pressure. Starting from high values at the early stages of compaction, the friction coefficient asymptotes to a lower value as the contact pressure (and density) is increased. Fig. 5 illustrates the variation of friction coefficient for two cases:

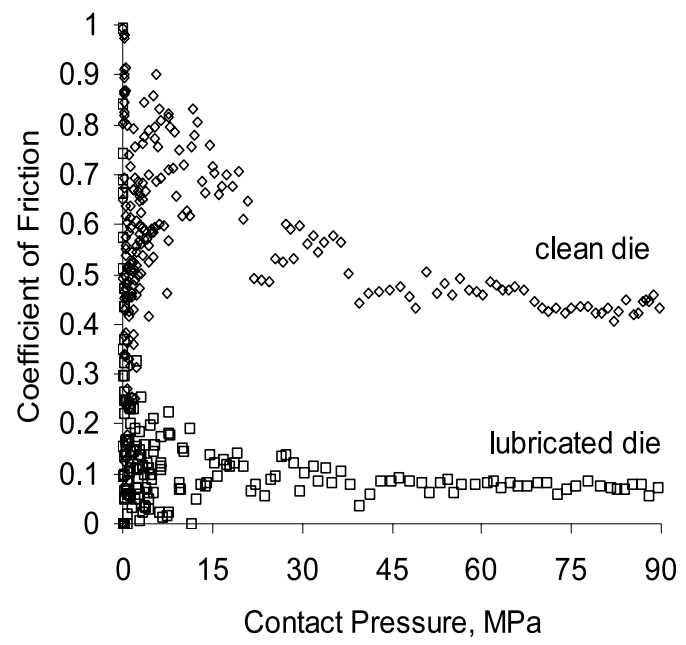

Fig. 5 Coefficient of friction between powder and die wall. This figure was published in Powder Technology, Vol. 133, Sinka I.C., Cunningham J.C. and Zavaliangos A., The effect of wall friction in the compaction of pharmaceutical tablets with curved faces: A validation study of the Drucker-Prager Cap model, 33-43, Copyright Elsevier (2003). 
1. Mean die wall condition, where the die wall is degreased prior to compaction,

E. lubricated die wall condition, where a tablet of pure lubricant powder (magnesium stearate) is compressed prior to the experiment.

The relevance of high and low friction between powder and die wall (and powder and punches) is illustrated in Example 1.

\subsection{Example 1: density distribution in curved- face pharmaceutical tablets}

The importance of density variations in powder compacts has been highlighted since the early 1900s, e.g. Train (1957). Experimental results by Macleod and Marshall (1977) have highlighted the importance of the friction between powder and die wall. The effect of friction on density variations in pharmaceutical tablets is discussed below.

For pharmaceutical tablets, the internal density distribution is important because it affects the local material properties, which in turn can influence the bioavailability of the drug and the mechanical properties of the tablets. The importance of numerical modelling was recognised by Khattat and Hassani (1987). The other contributing factors (material behaviour, geometry, loading sequence and initial conditions of the powder after die fill) have also been identified.

Before discussing the effect of density distribution on tablet strength and breakage, it is instructive to review the methods developed for measuring density distributions as these methods form the experimental basis for model validation. Earlier methods were based on differential machining, hardness tests or X-ray images of lead particles embedded in the powder and surface topography (Train and Hersey 1960; Kandeil and De Malherbe 1977; Sixsmith and McCluskey 1981; Charlton and Newton 1985; Ozkan and Briscoe 1996; Sinka et al., 2003; Eiliazadeh et al., 2004). More modern non-destructive techniques (Lannutti 1997) including X-ray CT and NMRI were also applied to characterise density distributions (Sinka et al., 2004a; Djemai and Sinka, 2006) and defects (Wu et al., 2005) in pharmaceutical tablets.

In the first example, we examine the density distributions in curved-face tablets (diameter $25 \mathrm{~mm}$, curvature radius $19.82 \mathrm{~mm}$ ) compressed using clean and pre-lubricated tooling, which give high and low friction coefficients between powder and tooling, respectively.

Fig. 6 illustrates the density variations in two tablets compressed to the same average relative density. The experimental density contours (Fig. 6a,b) were determined using indentation hardness mapping (Sinka et al., 2005). The numerical modelling was carried out by implementing the density-dependent Drucker-Prager model presented in Section 6.1 in the finite element package Abaqus Standard (Hibbit, Karlsson and Sorensen, 1988). (a)
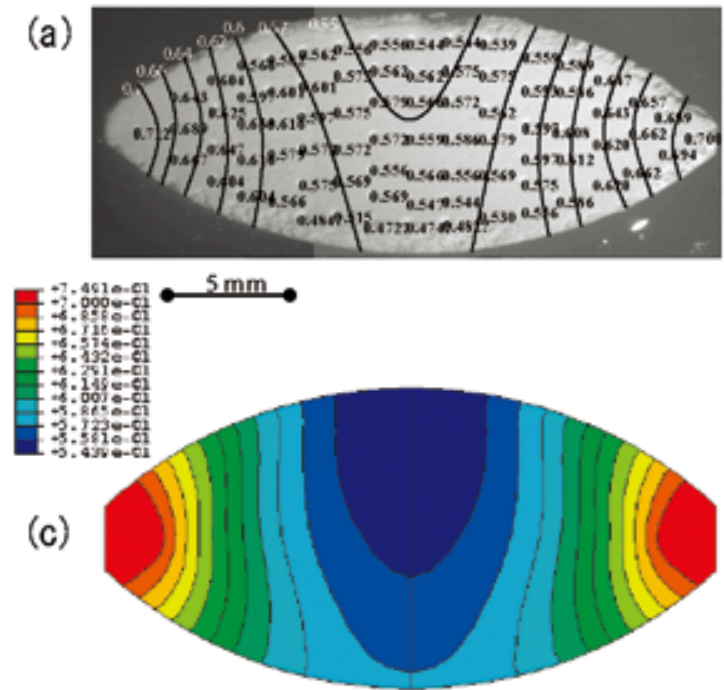

Clean (unlubricated) die and punches (b)
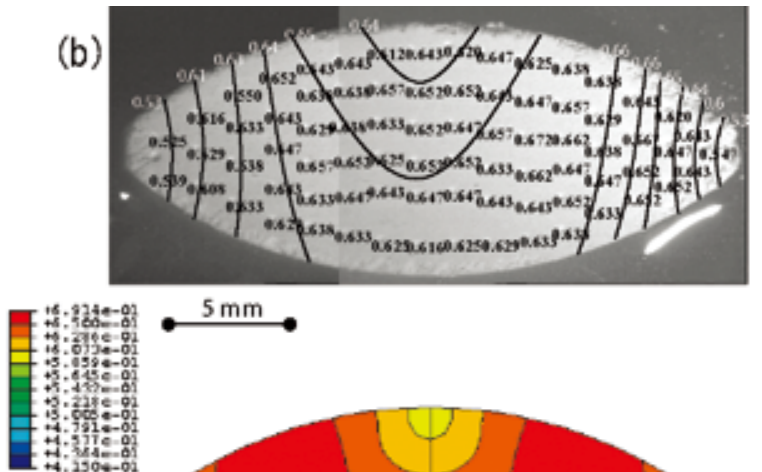

$5 \mathrm{~mm}$

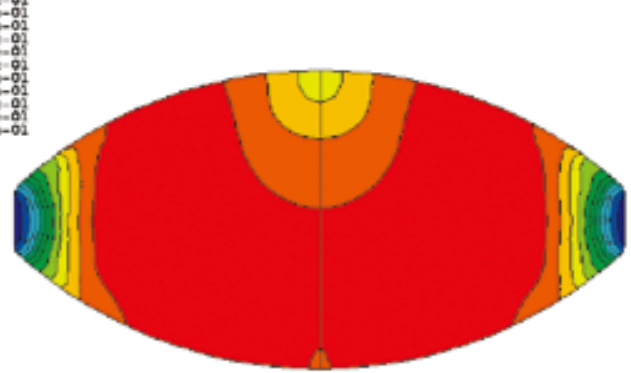

Lubricated die and punches

Fig. 6 Relative density distribution in 25-mm diameter curved-face tablets. Experimental data for tablet compressed using a) clean and b) lubricated tooling. Numerical results for c) high and d) low friction. This figure was published in Powder Technology, Vol. 133, Sinka I.C., Cunningham J.C. and Zavaliangos A., The effect of wall friction in the compaction of pharmaceutical tablets with curved faces: A validation study of the Drucker-Prager Cap model, 33-43, Copyright Elsevier (2003). 
athealow-friction (pre-lubricated die) case was modelled using variable friction data as presented in Fig.

$w^{2} 5$. For the high-friction case, the friction coefficient was taken as 0.5 (constant). The bottom punch was maintained stationary during the compression. The die was filled by hand with attention paid to obtaining a uniform initial packing in the powder bed.

The relative density distributions predicted by the model for the high- and low-friction cases are presented in Fig. 6c and $\mathbf{d}$, which are in good agreement with the experimental density maps.

Fig. 6 illustrates that it is possible to make two identical tablets in terms of shape, weight and material which have different microstructures depending on the friction conditions employed. The numerical modelling provides insight into the powder movement during compaction, which depends on friction and punch geometry. High friction hinders the relative sliding of the powder into the top punch cavity as the top punch makes progressive contact with the initially flat top surface of the powder. Although the powder movement is relatively complex, the highfriction case can be described as pressing columns of powders to different heights. Higher density regions therefore develop around the outer edge of the tablet due to the curvature of the punch.

If the friction coefficient is reduced (i.e. by prelubricating the die and punches before compaction),

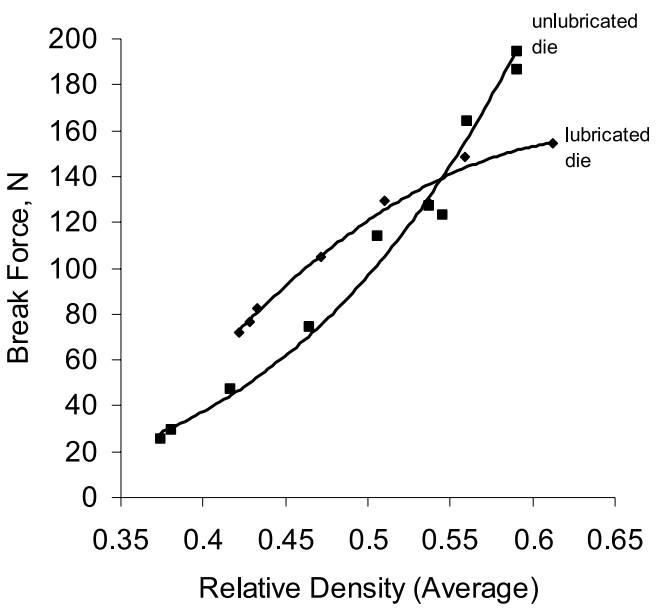

(a) then the relative sliding of the powder with respect to the punch face is facilitated. This results in a density distribution that is the inverse image of that for high friction, i.e. the density is highest in the middle of the tablet.

A practical question is: what is the effect of density distributions on tablet strength, friability, disintegration and failure behaviour (if any)? Fig. 7a presents diametrical compression experiments for tablets compacted to different densities using clean and prelubricated tooling, and illustrates that the strength is not unique. Fig. $\mathbf{7 b}$ presents the failure modes of the tablet during diametrical compression experiments, illustrating that the failure mode is dependent on the internal tablet structure (Sinka et al. 2004b).

Somewhat similar density patterns have been induced in tablets of a more representative size (8.7 $\mathrm{mm}$ diameter, punch curvature radius $8.03 \mathrm{~mm}$ ). A compaction force of $3 \mathrm{kN}$ was applied for compressing two microcrystalline cellulose tablets using clean and pre-lubricated tooling. The relative densities were 0.724 and 0.751 , respectively. It can be observed that the same compaction force produces higher average density if the friction is low. Fig. 8 illustrates the density distributions obtained experimentally using the NMRI technique (Djemai and Sinka, 2006) for these two tablets and the corresponding numerical modelling studies. The density patterns are consis-
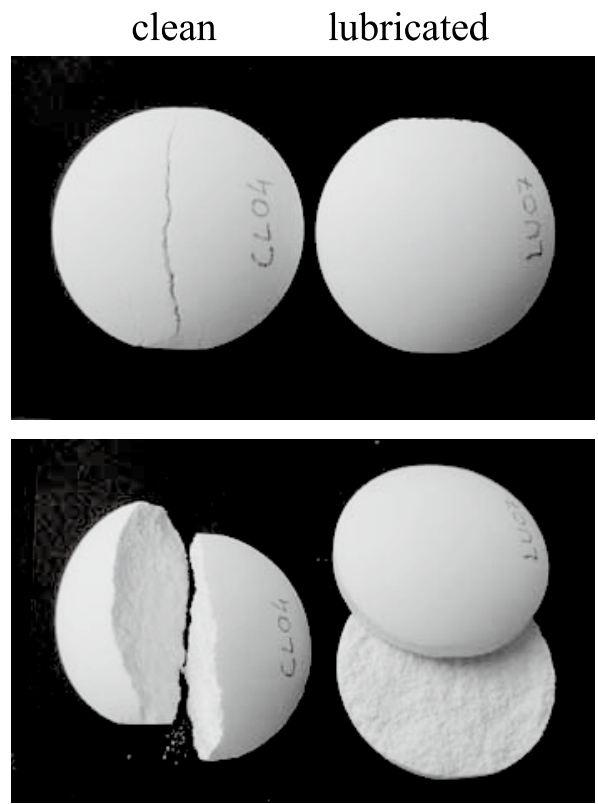

(b)

Fig. 7 Effect of microstructure on tablet behaviour; a) break force in diametrical compression experiments, b) failure mode for tablet compacted in clean and pre-lubricated dies. This figure was published in Journal of Pharmaceutical Sciences, Vol. 93, Sinka I.C., Cunningham J.C. and Zavaliangos A., Analysis of tablet compaction. Part 2 - Finite element analysis of density distribution in convex tablets, 2040-2052, Copyright Wiley-Liss, Inc. (2004). 


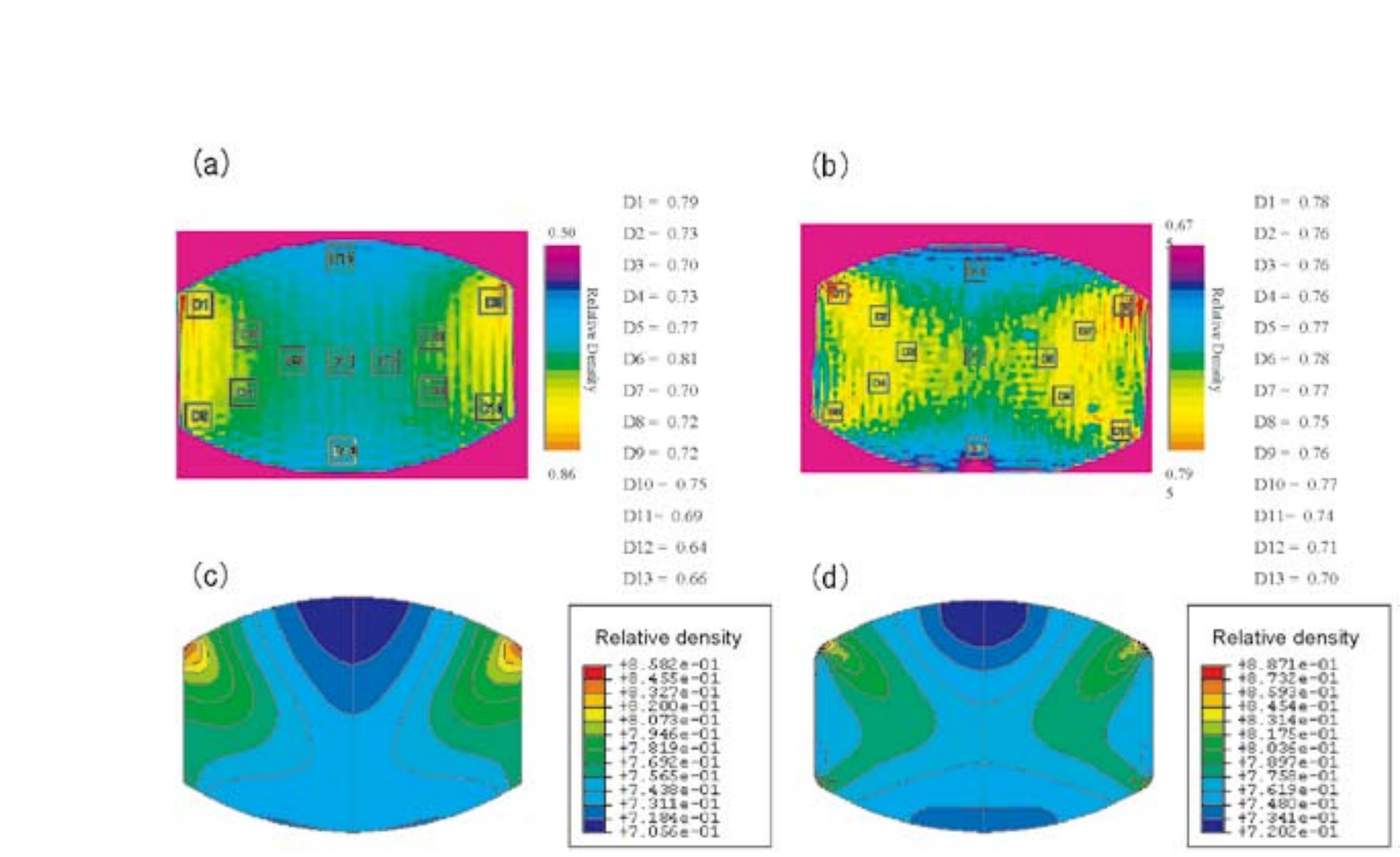

Fig. 8 Relative density distribution in 8.7-mm-diameter curved-face tablets. NMRI data for tablet compressed using a) clean and b) lubricated tooling. Numerical results for c) high and d) low friction.

tent with the observations for the 25-mm-diameter tablets discussed above. High friction results in highdensity regions around the outer circumference, whereas low friction facilitates more complex radial movement of the powder, resulting in a high-density region which has an X-shaped vertical cross-section. It can be speculated that this pattern could promote a cone-shaped crack formation; this is discussed in Example 4.

The density distribution in the 8.7-mm-diameter tablets presents features that are distinct from Fig. 6. For the high-friction case, the density around the upper circumference is higher than around the lower circumference. This pattern comes about from the punch motion: the lower punch is stationary. The effect is less pronounced for the 25-mm-diameter tablets where the initial height to diameter aspect ratio is lower. Further effects of density distribution on the strength, friability, abrasion and disintegration behaviour of tablets are discussed elsewhere (Sinka et al., 2007).

It is important to note that the density distribution and its effects on tablet properties depends on all 5 factors discussed in Section 3.2. The examples above highlight that generalisations are not always appropriate and that each situation should be considered individually.

\subsection{Example 2: bilayer tablets and compression coating}

In this section we discuss modelling issues for more complex tablet systems: bilayer tablets and compression coating. These dosage forms were developed for a number of reasons such as to co-administer two different drugs in the same dosage form, release the same drug at different rates or to modify the release property of a formulation.

The manufacturing process of bi-layer tablets requires special rotary presses (Pitt and Sinka, 2007) where the first layer is fed into the die and partially pressed, but not ejected from the die. Then the second layer is fed followed by compaction and ejection. This example focuses on the density distributions in the powder at various stages of the compaction process.

Numerical analysis has been carried out for a 20-mm-diameter bilayer tablet with flat faces. For both layers, microcrystalline cellulose was used, starting from an initial relative density of 0.3 . The first layer was compressed to $10 \mathrm{kN}$ and the second layer to $40 \mathrm{kN}$ as indicated in Fig. 9. The bottom punch was maintained stationary during the entire compression schedule.

Fig. 10 presents snapshots of the density variations at various stages during the process:

- Fig. 10a corresponds to the end of compression of the first layer. At this stage, we obtain a density 


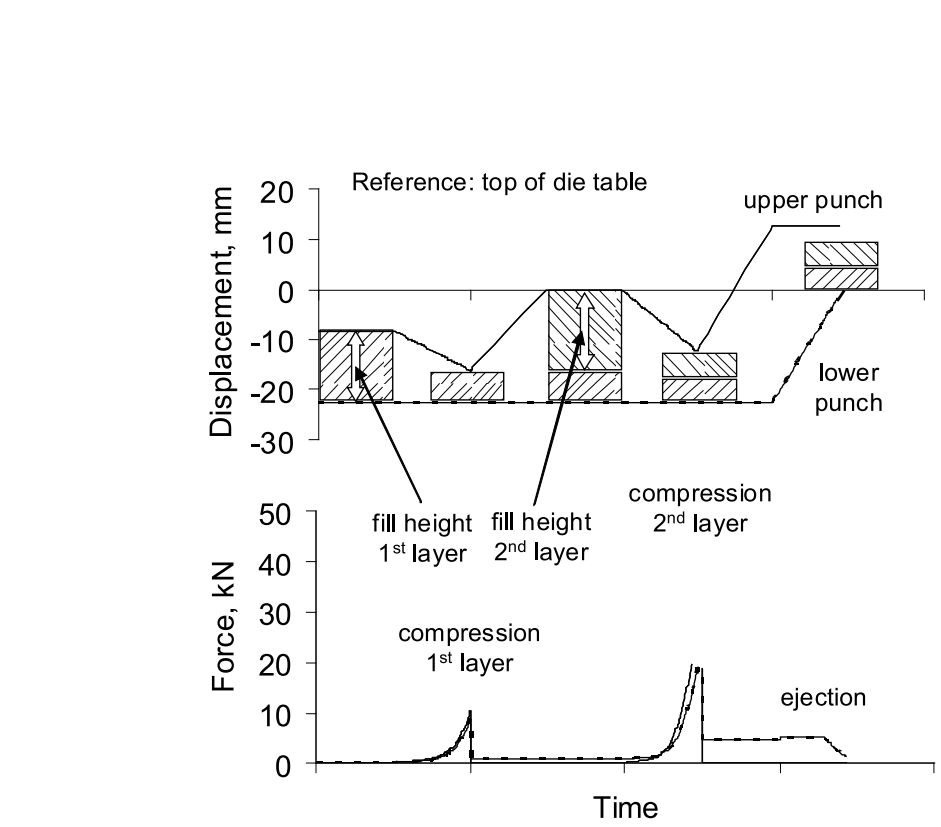

Fig. 9 Compression schedule for the bilayer tablet. This figure was published in Chapter 14: Modelling die compaction in the pharmaceutical industry, Sinka I.C. and Cocks A.C.F. (pp. 225-244) in: Modelling of Powder Die Compaction. Series: Engineering Materials and Processes Eds. P.R. Brewin, O. Coube, P. Doremus and J.H. Tweed. Copyright Springer (2007). With kind permission of Springer Science and Business Media.

distribution that is specific to a flat-faced tablet compressed such that the lower punch is stationary. In the present example, in order to accentuate frictional effects, the friction coefficient was set to 0.5 (constant), which is a relatively high value, specific to clean (unlubricated) die wall conditions.
- After compression of the first layer, the powder for the second layer is delivered into the die, Fig. 10b. The initial density of the second layer is uniform (this assumption is used in all examples discussed).

- Fig. 10c is a snapshot of the density distribution during bilayer compaction. At this stage, densification occurs in the second (top) layer only and the density distribution in the first layer has not yet changed. Concurrent densification of both layers occurs only after the second layer reaches a similar state as the first layer, which occurs approximately when the compaction force reaches the value used to compress the first layer ( $10 \mathrm{kN}$ in this case).

- Density distribution at the end of compression of the bilayer tablet (40 $\mathrm{kN}$ force). The mismatch at the die wall gradually disappears towards the end of the bilayer compaction. In the final stage it is also interesting to note that the interface between the two layers becomes distorted. The top surface of the first layer becomes concave and the model predicts a variation in height of $0.5 \mathrm{~mm}$ for the input data used in the simulation. The prediction of face curvature can be verified experimentally by performing a tensile test, which results in separation at the interface.

The interface properties are important as they affect the strength and properties of the bilayer tablet. (a)

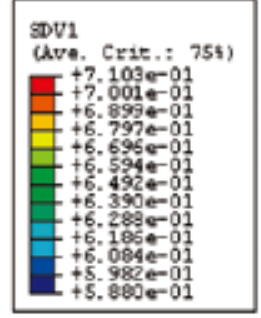

(c)

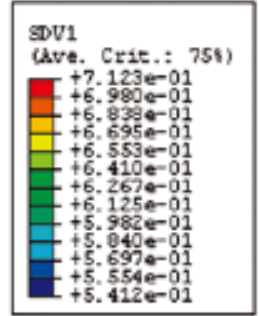

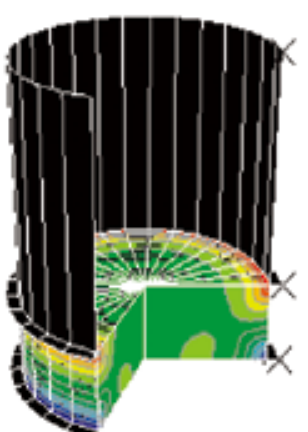

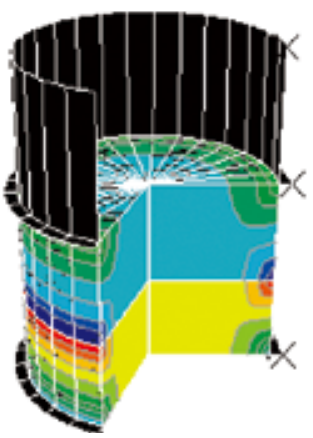

(b)
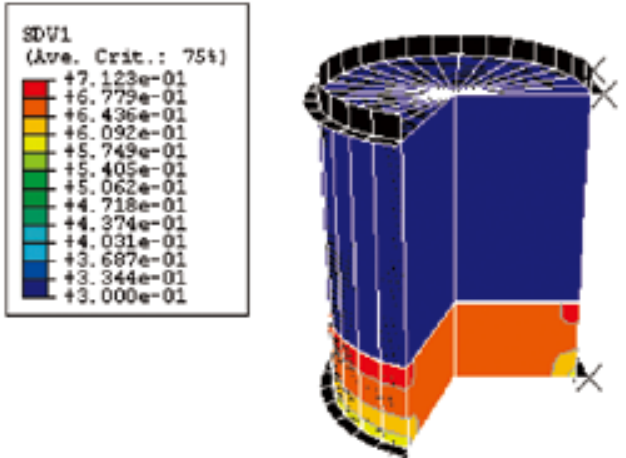

(d)

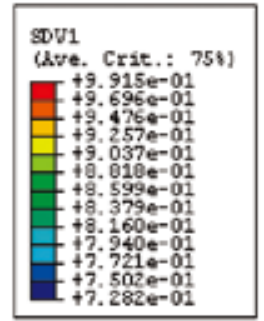

Fig. 10 Density distribution in bilayer tablets during compaction, a) end of first layer compaction, b) after the second layer was filled, c) snapshot during bilayer compression, d) end of bilayer compression. 


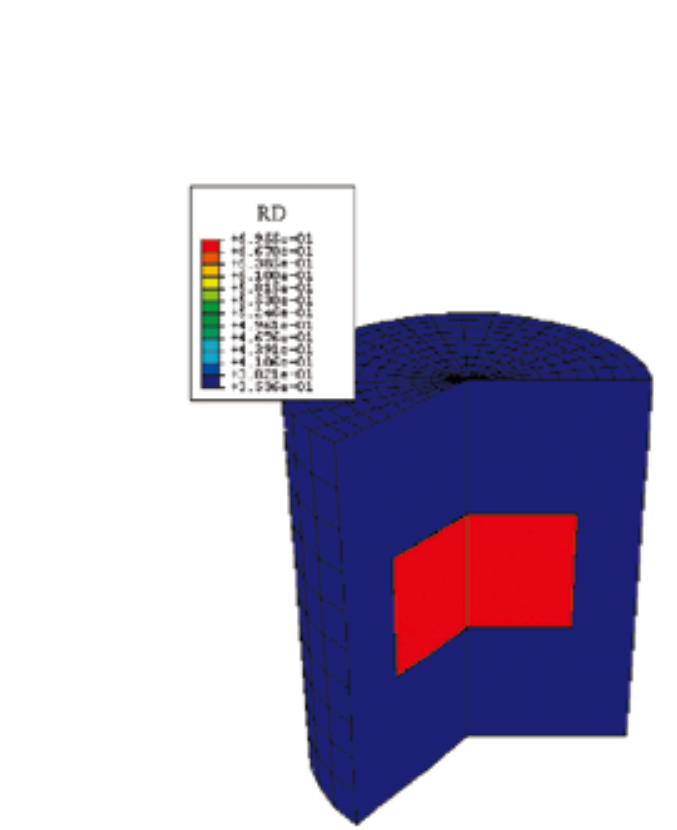

Initial relative density: core: 0.6955 coating: 0.3536

(a)

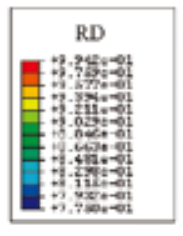

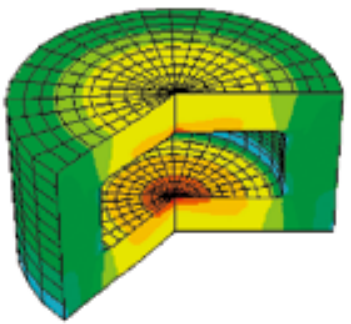

Coating only
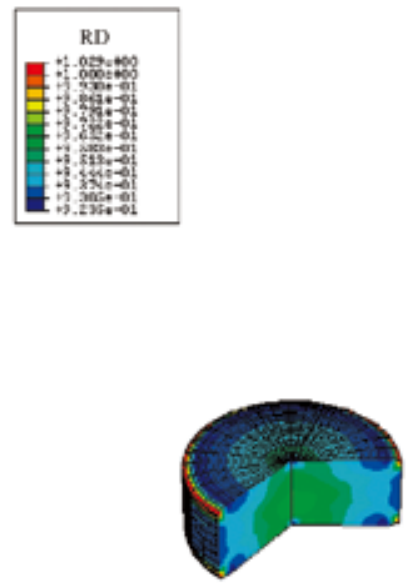

Core only

(b)

(c)

Fig. 11 Density distribution in a compression-coated tablet system, a) initial relative density 0.6955 and 0.3536 in core and coating, respectively, b) density distribution in the coating after compression, c) density distribution in core after compression. This figure was published in Chapter 14: Modelling die compaction in the pharmaceutical industry, Sinka I.C. and Cocks A.C.F. (pp. 225-244) in: Modelling of Powder Die Compaction. Series: Engineering Materials and Processes Eds. P.R. Brewin, O. Coube, P. Doremus and J.H. Tweed. Copyright Springer (2007). With kind permission of Springer Science and Business Media.

In the above analysis, the interaction between the two layers was described as frictional sliding using a high friction coefficient (0.5). In practice, an adhesive normal interaction also develops between the layers. A comprehensive analysis of the stress states during compression, unloading and ejection requires more detailed experimental characterisation of the interlayer strength as well as numerical implementation. The problem of layered compacts has relevance to other industries and products as well, e.g. detergents.

A particular case of bilayer compression is represented by the so-called compression coating process, which involves enclosing a smaller tablet (core) into a larger one (coating). In this case, a partially compressed tablet (formulation 1) is enclosed into a powder bed (formulation 2) as illustrated in Fig. 11a. After compression, tablet 1 is completely enclosed in tablet 2. Complex tablet systems can be designed using variations of layered and compression-coated systems. Tri-layer tablets and three nesting tablet systems have been developed.

The compression of a microcrystalline cellulose core (initial relative density 0.6955 ) in a bed of the same material (initial relative density 0.3536 ) is illustrated in Fig. 11. At the end of compression the material in the core reaches near full density. The material in the core is compressed to near full density. However, the regions around the vertical edges of the coating only reach a relative density of the order of $0.75-0.8$. This illustrates that the chosen geometry is not optimal. Lower-density areas implies lower strength, which makes fractures possible. Commercial core-coated tablets have curved faces that facilitate powder movement around the core. Detailed analysis of all stages of the problem can identify the conditions which are favourable for defect formation during compression, unloading, ejection, or subsequent handling. Thus numerical modelling can be used to optimise the geometry and initial pre-compression of the core as well as material properties and process parameters. A more detailed discussion on modelling bilayer tablets and compression coating is given elsewhere (Sinka and Cocks, 2007c).

\subsection{Example 3: deformation plasticity model}

The deformation plasticity framework is summarised in Section 4.3. Fig. 3 illustrates that contours of constant complementary work done per unit initial volume could be constructed based on triaxial test data. A detailed form of a suitable potential function was proposed (Sinka and Cocks, 2007a) for steel powders. However, this form is complex given that 


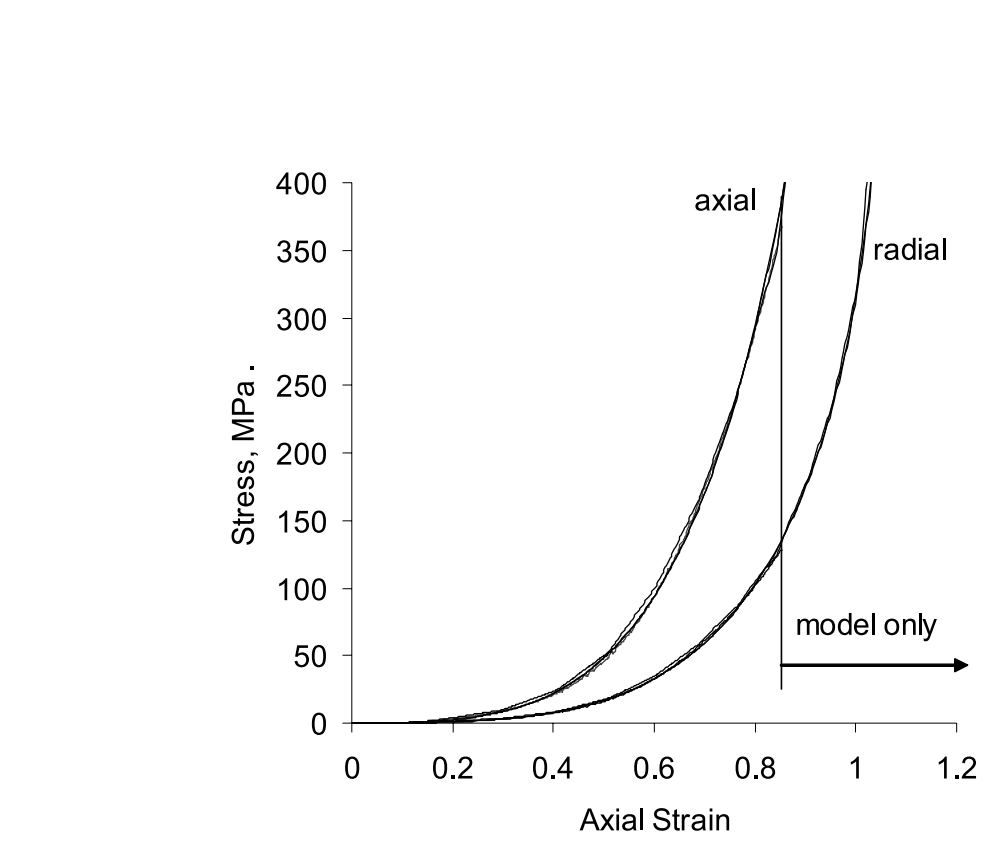

Fig. 12 Radial and axial stress during die compaction of calcium phosphate.

the contours in Fig. 3 are not self-similar. Ceramic and hard metal powders exhibit a simpler behaviour. For this class of powders the contours of constant complementary work are self-similar (Sinka and Cocks, 2007b), which could be described using a simple potential function that can be implemented in the Abaqus finite element package.

Fig. 12 illustrates the radial and axial stress evolution during die compaction of calcium phosphate. This material is a ceramic-like powder and is used as an excipient in pharmaceutical tablet compaction.

The experimental data were used to calibrate the deformation plasticity model (Sinka and Cocks, 2007b). Using the same set of data, a Drucker-Prager cap model was also calibrated. Fig. 12 presents the radial and axial stress traces for the experimental data, the prediction of the deformation plasticity model and the prediction of the Drucker-Prager cap model for die compaction. The traces overlap, which is not surprising as both models were calibrated using the same data. Fig. 12 nevertheless suggests that the implementation of both deformation and incremental plasticity models is correct.

The deformation plasticity model was calibrated also for alumina powder. Fig. 13 illustrates the application of the deformation plasticity model to the compaction of a ring with an outside diameter of 30 $\mathrm{mm}$ and an inside diameter of $10 \mathrm{~mm}$. The tooling is composed of a die, a central rod, and upper and lower punches, which are modelled as rigid surfaces. For this geometry, any density variations come about from the friction interaction between powder and tooling (we used a friction coefficient of 0.1 for all contact surfaces), and the pressing sequence (here the lower punch was prescribed stationary) as the initial relative density (0.35) was assumed constant.

Snapshots of the evolution of internal density distribution during compaction are presented in Fig. 13 in a vertical cross-section of the compact. Density variations in ceramic compacts are important as they influence the shrinkage behaviour during sintering.

\subsection{Example 4: crack development}

In the final set of examples, we discuss the important issue of crack formation, which is common across the powder pressing industries. Wu et al. (2005) employed X-ray CT to identify crack formation in round tablets with flat faces made using lactose powder, which is used as an excipient in pharmaceutical tablet formulation.

Capping (or crack formation) is a common defect in pharmaceutical formulations of low mechanical strength and consists of a cone-shaped failure as illustrated in Fig. 14. Numerical modelling studies conducted by Wu et al. (2005) using the Drucker-Prager

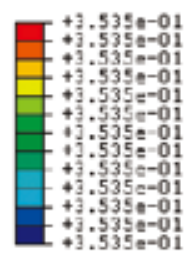

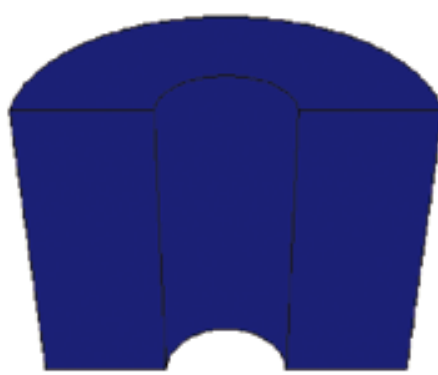

(a)
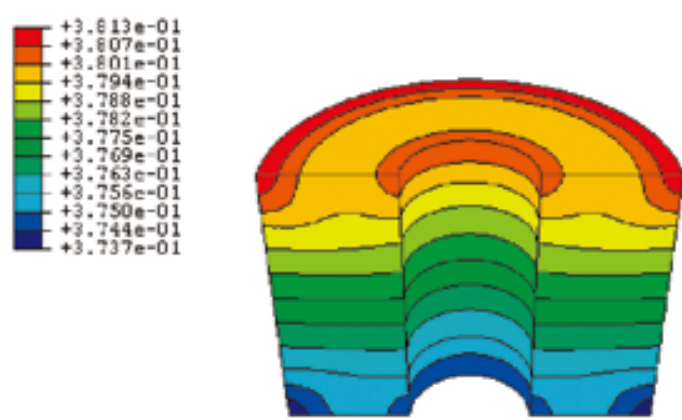

(b)

Fig. 13 Density distribution during die compaction of an alumina ring. 


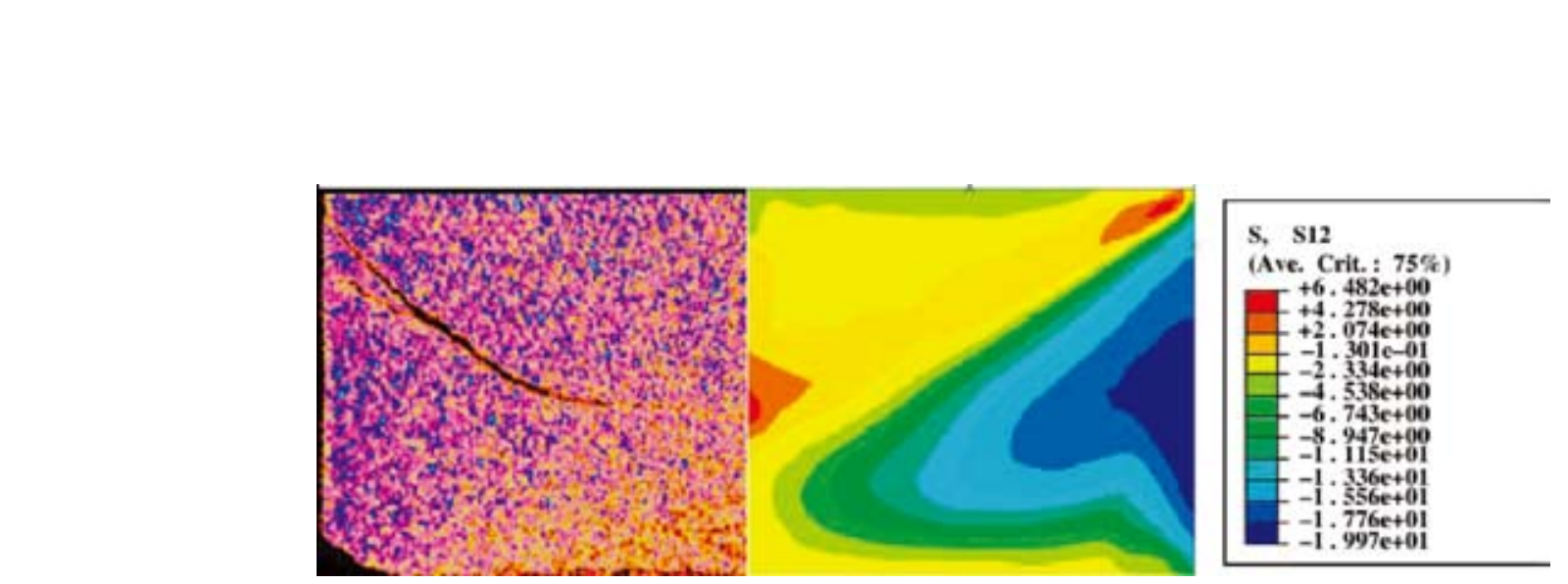

Fig. 14 Crack development in pharmaceutical tablets, vertical cross-section shown. This figure was published in Powder Technology (In Press, Corrected Proof), Wu C.-Y, Hancock B.C., Mills A., Bentham A.C., Best S.M. and Elliott J.A., Numerical and experimental investigation of capping mechanisms during pharmaceutical tablet compaction, Copyright Elsevier (2006).

cap model demonstrated that capping occurs due to the development of intensive shear bands during unloading. Fig. 14 illustrates the shear stresses during unloading alongside the crack identified by X-ray CT.

Further finite element studies by Wu et al. (2006) examined the effect of powder die-wall friction and pressing sequence, and concluded that capping could not be eliminated by operating upon these factors.

Coube and Riedel (2000) examined the causes of crack formation in multilevel parts compressed from metal powders. They employed a modified DruckerPrager model where the constitutive parameters were expressed as functions of density. The density distribution in the compact in Fig. 15 was in good agreement with experimental results (Kergadallan et al., 1997). This compact was also used in the benchmark study summarised in Section 4.1.

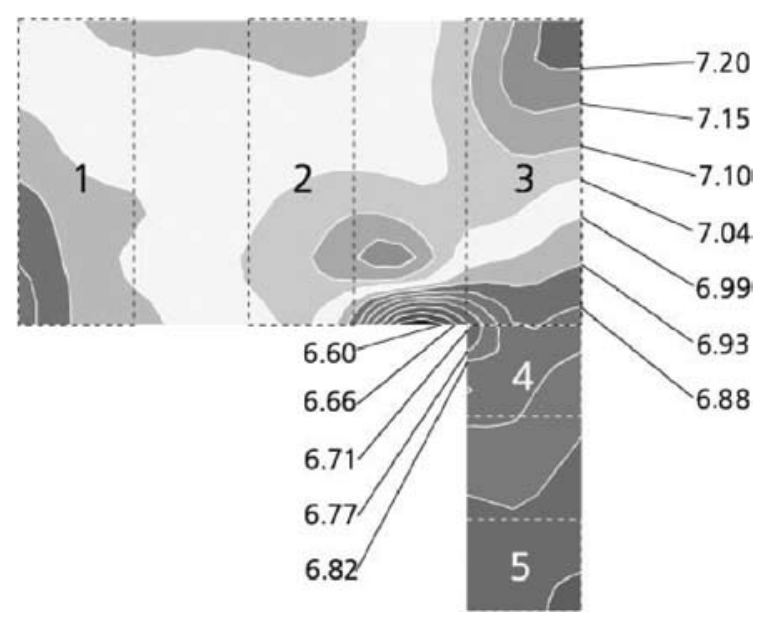

Fig. 15 Crack development in multilevel parts made of metallic powder. This figure was published in Powder Metallurgy, Vol. 43, Coube O. and Riedel H., Numerical simulation of metal powder die compaction with special consideration to cracking, 123-131, Copyright Maney Publishing (2000).
Coube and Riedel (2000) noted that the models employed are capable of accurately predicting the density distributions in green parts. While such simulations can be indicative of the risk of crack formation, it cannot definitively predict whether or not a crack would indeed develop.

\section{Final Remarks}

Powder compaction is a complex engineering process. The material undergoes a transformation from a loose powder state to a dense compact, thus physics-based constitutive models are inherently complicated. Similarly, the friction between powder and die wall requires appropriate description. Complex multilevel parts that are typical to powder metallurgy require expensive tooling and an appropriate selection of punch motions to avoid crack formation during powder transfer, compaction, unloading and ejection from the die. Early developments in powder compaction modelling were motivated by replacing empiricism and trial and error in tool design and pressing sequence set-up.

The development, calibration, implementation and validation of constitutive models has matured over the last decade. Models today are capable of predicting density distributions and tool loading with sufficient accuracy for practical use. A number of outstanding issues, however, remain. As described in Section 6.6, current models can give only an indication of crack formation. Also, the failure patterns in Fig. 7 cannot be predicted using isotropic models.

Crack formation in pharmaceutical tablets is further complicated by the high compression rate used in industrial tableting. Pharmaceutical powders are light, having a true density in the region of 1.5-2.5 $\mathrm{kgm}^{-3}$. In addition, their initial relative density 

pressure build-up within the pore space can be of a magnitude that is comparable with the local strength of the material. At a more fundamental level, a better understanding of the processes requires insight into complex phenomena occurring at various length scales from particle contacts to product. Multi-scale modelling approaches are therefore currently the subject of intense research.

At this moment in time, compaction models cannot predict each and every product property or performance measure that has practical relevance. Nevertheless, the models offer unique insights into the relationships between material properties and process parameters. Significant progress has also been made in establishing relationships between material and process parameters. The examples above illustrate that numerical models are able to offer a rational basis for and a practical tool to guiding the optimisation effort in product, process and tool design in powder compaction.

\section{Acknowledgements}

I am grateful to Professors Alan C.F. Cocks (University of Oxford) and Antonios Zavaliangos (Drexel University) for introducing me to this field.

\section{References}

Adams, M.J., Briscoe, B.J. and Pope, L., 1987. A contact mechanics approach to the prediction of the wall friction of powders. In Tribology in particulate technology, Briscoe B.J. and Adams M.J. (Eds.), Adam Hilger IOP Publishing Ltd., pp.8-22.

Akisanya, A. R., Cocks, A.C.F. and Fleck, N.A., 1997. The yield behaviour of metal powders. International Journal of Mechanical Sciences, Vol. 39, Issue. 12, pp. 1315-1324.

Aydin, I., Briscoe, B.J. and Ozkan, N., 1997. Modeling lowder compaction: A Review. Materials Research Society Bulletin Vol. 22, No. 2, pp.45-51.

Bagi, K., 1993. A quasi-static numerical model for microlevel analysis of granular assemblies. Mechanics of Materials, Vol. 16 Issues 1-2, pp. 101-110.

Brown, S.B. and Weber, G.A., 1988. A constitutive model for the compaction of metal powders. Modern Developments in Powder Metallurgy, Vols. 18-21, pp. 465-476.

Budiansky, B., 1959. A reassessment of deformation theory of plasticity, Journal of Applied Mechanics, Vol. 26, pp. 259-264.

Charlton, B.J. and Newton, M., 1985. Application of gammaray attenuation to the determination of density distribu-

tions within compacted powders. Powder Technology, Vol. 41, pp. 123 -134.

Cocks, A.C.F. 2001. Constitutive modelling of powder compaction and sintering. Progress in Materials Science vol. 46(3-4): 201-229.

Cocks, A.C.F. and Sinka, I.C., 2007. Constitutive modelling of powder compaction - I. Theoretical concepts. Mechanics of Materials, Vol. 39, pp. 392-403.

Cocks, A.C.F., 2008, Chapter 3: Mechanics of Powder Compaction In Modelling of Powder Die Compaction, Series: Engineering Materials and Processes, Eds. P. R. Brewin, O. Coube, P. Doremus and J. H. Tweed, Springer, pp. $31-42$.

Cocks, A.C.F., Gethin, D., Häggblad, T. Kraft, T. and Coube, O., 2008, Chapter 4: Compaction Models, ibid. pp. 43-66.

Coube, O. and Riedel, H., 2000. Numerical simulation of metal powder die compaction with special consideration to cracking. Powder Metallurgy, Vol. 43, No. 2, pp.123-131.

Cundall, P.A. and Strack, O.D.L., 1979. A discrete numerical model for granular assemblies. Geotechniques, Vol. 29, No.1, pp.47-65.

Cunningham, J.C., Sinka, I.C. and Zavaliangos, A., 2004, Analysis of tablet compaction, Part 1 - Characterisation of mechanical behavior of powder and powder/tooling friction, Journal of Pharmaceutical Sciences, Vol. 93, pp. 2022-2035.

DeLo, D.P., Dutton R.E. and Semiatin S.L., 1999. A comparison of discrete element model predictions to observations of metal powder consolidation. Scripta Materialia, Vol. 40, Issue 10, 23 pp. 1103-1109.

DiMaggio, F.L. and Sandler, I.S, 1971. Material model for granular soils. Journal of Engineering Mechanics Division, Proceedings of the American Society of Civil Engineering, Vol. 97, No. 3, pp. 935-950.

Djemai, A. and Sinka, I.C., 2006. Nuclear magnetic resonance imaging of density distributions in tablets. International Journal of Pharmaceutics. Vol. 319, Issues 1-2, pp. $55-62$.

Doremus, P., Geindreau, C., Martin A., Debove L., Lecot R. and Dao M., 1995. High pressure triaxial cell for metal powder. Powder Metallurgy. 38, pp. 284-287.

Drucker, D.C. and Prager, W., 1952. Soil mechanics and plastic analysis or limit design, Quarterly Applied Mechanics. Vol. 10, pp. 157-165.

Eelkman, Rooda, J. and G. Haaker, 1977. A testing procedure for triaxial tests and a numerical method for the calculation of powder flow properties. Powder Technology Vol. 16: 273-280.

Eiliazadeh, B., Pitt, K., Briscoe, B.J., 2004. Effects of punch geometry on powder movement during pharmaceutical tableting processes. International Journal of Solids and Structures, Vol. 41, No 21, pp. 5967-5977.

Ernst, E. and Barnekow, D., 1994. Pressure, friction and density during axial powder compaction. Proc. PM ' 94 World Congress on Powder Metallurgy, Les Ulis, Les Editions de Physique, Vol. 1, pp.673-676.

Fleck, N.A., Kuhn, L.T. and McMeeking, R.M., 1992. Yield- 
ing or metal powder bonded by isolated contacts. Journal dof the 9 Mechanics and Physics of Solids, Vol. 40, No. 5, wo.1139-1162.

Fleck, N.A., 1995. On the cold compaction of powders. Journal of the Mechanics and Physics of Solids, Vol. 43, No. 9, pp.1409-1431.

Fleck, N.A., Storakers, B. and McMeeking, R.M., 1997. The viscoplastic compaction of powders. In: N.A. Fleck and A.C.F. Cocks, Editors, Mechanics of Granular and Porous Materials, Kluwer, pp. 1-10.

Gearing, B.P., Moon, H.S. and Anand, L., 2001. A plasticity model for interface friction: application to sheet metal forming. International Journal of Plasticity; Vol. 17, pp. 237-271.

Gurson, A.L., 1977. Continuum theory of ductile rupture by void nucleation and growth: Part I - yield criteria and flow rules for porous ductile media. Journal of Engineering Materials and Technology; Transactions of the ASME; January, pp.2-15.

Hassanpour, A. and Ghadiri, M., 2004. Distinct element analysis and experimental evaluation of the Heckel analysis of bulk powder compression. Powder Technology, Volume 141, pp. 251-261.

Heyliger, P.R. and McMeeking, R.M., 2001. Cold plastic compaction of powders by a network model. Journal of the Mechanics and Physics of Solids, Vol. 49 (9), pp. 2031-2054.

Hibbitt, Karlsson and Sorensen, Inc., 1988. Abaqus theory manual.

Kamath, S. and Puri, V. M., 1997. Measurement of powder flow constitutive model parameters using a cubical triaxial tester. Powder Technology, Vol. 90, pp. 59-70.

Kandeil, A. and De Malherbe, M. C., 1977. The use of hardness in the study of compaction behaviour and die loading. Powder Technology, vol. 17, 253-257.

Kergadallan, J., Puente, G., Doremus, P and Pavier, E., 1997. Compression of an axisymmetric part with an instrumented press. Proc. International Workshop on Modelling of Metal Powder Forming Processes, Grenoble, France, 21-23 July, pp.277-285.

Khattat, I.M. Al- and Hassani, S.T. Al-, 1987. Towards a computer aided analysis and design of tablet compaction. Chemical Engineering Science, Vol. 42, No.4, pp.702-712.

Khoei, A.R., Azami, A.R. and Azizi, S., 2007. Computational modeling of 3D powder compaction processes. Journal of Materials Processing Technology Vol. 185(1-3): pp. 166-172.

Kitahara, H., Kotera, H. and Shima, S., 2000. 3-D simulation of magnetic particles' behaviour during compaction in a magnetic field. Powder Technology, Vol. 109, pp. 234-240.

Kong, C.M. and Lannutti, J.J., 2000. Localized densification during the compaction of alumina granules: the stage I-II transition. Journal of the American Ceramic Society Vol. 83 (4), pp. 685-690.

Kremer, D.M. and Hancock, B.C., 2006. Process simulation in the pharmaceutical industry: a review of some basic physical models. Journal of Pharmaceutical Sciences, Vol. 95, No.3, pp.517-529.

Kuhn, H.A. and Downey, C.L., 1973. Material behaviour in powder preform forging, Journal of Engineering Materials and Technology, pp. 41-46.

Landry, J.W., Grest, G.S., Silbert, L.E. and Plimpton, S.J., 2003. Confined granular packings: structure, stress, and forces. Physical Review, E Vol. 67, 041303.

Lannutti, J.J., 1997. Characterisation and control of compact microstructure. MRS Bulletin, 22, pp. 38-44.

Lee, S. C. and Kim, K.T., 2007. A study on the Cap model for metal and ceramic powder under cold compaction." Materials Science and Engineering: A Vol. 445-446: pp. 163-169.

Lewis, R.W., Gethin, D.T., Yang, X.-S. and Rowe R.C., 2005. A combined finite-discrete element method for simulating pharmaceutical powder tableting. International Journal of Numerical Methods in Engineering, Vol. 62, pp. 853-869.

Macleod, H.M. and Marshall, K., 1977. The determination of density distributions in ceramic compacts using autoradiography. Powder Technology, Vol. 16, pp. 107-122.

Mallender, R.F., Dangerfield, C.J and Coleman, D.S., 1974. The variation of coefficient of friction with temperature and compaction variables for iron powder stearatelubricated systems. Powder Metallurgy, Vol. 17, No. 34, pp.288-301.

Martin, C.L., Bouvard, D. and Shima, S., 2003. Study of particle rearrangement during powder compaction by the discrete element method. Journal of the Mechanics and Physics of Solids Vol. 51 (4), pp. 667-693.

Mirghasemi, A.A., Rothenburg, L. and Matyas, E.L., 2002. Influence of particle shape on engineering properties of assemblies of two-dimensional polygon-shaped particles. Geotechnique Vol. 52, pp. 209-217.

Mosbah, P., Bouvard, D., Ouedraogo, E and Stutz, P., 1997. Experimental techniques for analysis of die pressing and ejection of metal powder. Powder Metallurgy, Vol. 40, No. 4, pp.269-277.

Nedderman, R. M., 1992. Statics and kinematics of granular materials. Cambridge University Press.

Oda, M. and Iwashita, K., 1999. Mechanics of Granular Materials. Balkema Publishers, Rotterdam, Netherlands.

Oda, M. and Iwashita, K., 2000. Study on couple stress and shear band development in granular materials based on numerical simulation studies. International Journal of Engineering Science. Vol. 38, pp. 1713-1740.

Ozkan, N.B. and Briscoe, J., 1996. The surface topography of compacted agglomerates; a means to optimise compaction conditions. Powder Technology, Vol. 86, pp. 201-207.

Pavier, E. and Doremus, P., 1997. Friction behavior of an iron powder investigated with two different apparatus. International Workshop on Modelling of Metal Powder Forming Processes, Grenoble, France, 21-23 July, pp.335-344.

Pitt, K. and Sinka, I.C., 2007. Chapter 16: Tableting. In: Granulation (Handbook of Powder Technology, Volume 

of powder compaction for two multilevel ferrous parts, including powder characterisation and experimental validation. Powder Metallurgy, Vol. 45, No. 4, pp.335344.

Ponter, A.R.S. and Martin, J.B., 1972. Some extremal properties and energy theorems for inelastic materials and their relationship to the deformation theory of plasticity. Journal of the Mechanics and Physics of Solids, Vol. 20, pp.281-300.

Procopio, A.T. and Zavaliangos, A., 2005. Simulation of multi-axial compaction of granular media from loose to high relative densities. Journal of the Mechanics and Physics of Solids, Vol. 53, Issue 7, pp. 1523-1551.

Ransing, R. S., Gethin, D. T., Khoei, A. R., Mosbah, P. and Lewis, R. W., 2000. Powder compaction modelling via the discrete and finite element method Materials \& Design, Volume 21, Issue 4, 1, pp. 263-269.

Redanz, P. and Fleck, N.A., 2001. The compaction of a random distribution of metal cylinders by the discrete element method. Acta Materialica Vol. 49, pp. 4325-4335.

Roure, S., Bouvard, D., Doremus, P. and Pavier, E., 1999. Analysis of die compaction of tungsten carbide and cobalt powder mixtures, Powder Metallurgy, Vol. 42, No. 2, pp.164-170.

Samimi, A., Hassanpour, A. and Ghadiri, M., 2005. Single and bulk compressions of soft granules: Experimental study and DEM evaluation. Chemical Engineering Science, Vol. 60, Issue 14, pp. 3993-4004.

Schneider, L. and Cocks, ACF, 2002. An experimental investigation of the yield behaviour of metal powder compacts. Powder Metallurgy, Vol. 45, No.3, pp.237-245.

Schofield, A. and Wroth, C.P., 1968. Critical State Soil Mechanics, McGraw-Hill.

Shima, S. and Oyane, M., 1976. Plasticity theory for porous metals, International Journal of Mechanical Sciences. Vol. 18, pp. 85-291.

Shima, S., Kotera, H., Mosbah, P. and Kojima, J., 1997. A Study of mechanical behaviour of iron powders by three- and two-dimensional compaction. Proc. International Workshop on Modelling Metal Powder Forming Processes, Grenoble, France, pp. 9-17.

Sinka, I.C., Cocks, A.C.F., Morrison, C.J. and Lightfoot, A., 2000. High Pressure triaxial facility for powder compaction. Powder Metallurgy, Vol. 43, No. 3, pp.253-262.

Sinka, I.C., Cocks, A.C.F. and Tweed, J.H., 2001. Constitutive data for powder compaction modelling. Journal of Engineering Materials and Technology, Vol. 123, No. 2, pp.176-183.

Sinka, I.C., Cunningham, J.C. and Zavaliangos, A., 2003. The effect of wall friction in the compaction of pharmaceutical tablets with curved faces: A validation study of the Drucker-Prager Cap model. Powder Technology, Vol. 133, pp. 33-43.

Sinka, I.C., Burch, S.F., Tweed, J.H. and Cunningham, J.C., 2004a. Measurement of density variations in tablets us-

ing X-ray computed tomography. International Journal of Pharmaceutics. Vol. 271, pp. 215-224.

Sinka, I.C., Cunningham, J.C. and Zavaliangos, A., 2004b. Analysis of tablet compaction. Part 2-Finite element analysis of density distribution in convex tablets. Journal of Pharmaceutical Sciences. Vol. 93, No. 8, pp. 2040-2052.

Sinka, I.C. and Cocks, A.C.F., 2007a. Constitutive Modelling of Powder Compaction - II. Evaluation of Material Data. Mechanics of Materials, Vol. 39, pp. 404-416.

Sinka, I.C. and Cocks, A.C.F., 2007b. Strategies for modelling of die compaction of powders. Proc. COMPLAS 2007, IX international Conference on Computational Plasticity Fundamentals and Applications, Barcelona 5-7 September 2007. Vol. 1, pp. 298-302.

Sinka, I.C. and Cocks, A.C.F., 2007c. Chapter 14: Modeling die compaction in the pharmaceutical industry. In: Modelling of Powder Die Compaction. Series: Engineering Materials and Processes Eds. P.R. Brewin, O. Coube, P. Doremus and J.H. Tweed. Springer, pp. 225-244.

Sinka, I.C., Pitt, K.G. and Cocks, A.C.F., 2007. Chapter 22: The strength of pharmaceutical tablets. In: Particle Breakage. Eds. A.D. Salman, M.J. Hounslow and M. Ghadiri. Elsevier, pp. 941-970.

Sixsmith, D. and McCluskey, D., 1981. The effect of punch tip geometry on powder movement during the tableting process. J. Pharm. Pharmacol, Vol. 33 , pp. 79-81.

Thornton, C. and Antony, S.J., 2000. Quasi-static shear deformation of a soft particle system. Powder Technology. Vol. 109, pp. 179-191.

Thornton, C. and Zhag, L., 2003. Numerical simulations of the direct shear test. Chemical Engineering \& Technology Vol. 26, pp. 153-156.

Train, D. and Hersey, J. A., 1960. Some fundamental studies into the cold compaction of plastically deforming solids. Powder Metallurgy, Vol. 6, pp. 20-35.

Train, D., 1957. Transmission of forces through a powder mass during the process of pelleting. Transaction of the Institution of chemical Engineers., Vol 35, pp.258-266.

Trasorras, J.R.L, Parameswaran R. and Cocks A.C.F, 1998. Mechanical Behaviour of Metal Powders and Compaction Modelling. ASM Handbook, Vol. 7, Powder Metal Technologies and Applications; ASM International, pp.326-342.

Tsuji, Y., Kawaguchi, T. and Tanaka, T., 1993. Discrete particle simulation of two-dimensional fluidized bed. Powder Technology, Vol. 77, pp. 79-87.

Tuzun, U. and Heyes, D.M., 1997. Distinct element simulations and dynamic microstructural imaging of slow shearing granular flows. In: N.A. Fleck, A.C.F. Cocks (Eds.), Mechanics of Granular and Porous Materials, pp. 263-274.

Tvergaard, V., 1981. Influence of voids on shear band instabilities under plane strain condition. International Journal of Fracture Mechanics, Vol. 17, pp.389-407.

Tzaferopoulos, M.A., 1996. On a quasi-static discrete element model of granular materials. Computers and Geotechnics. Vol. 18, pp. 145-165. 
Wikman, Bg. Haggblad, H.A. and Oldenbirg, M., 1997. deModelling of powder-wall friction for simulation of iron wiowder pressing. International Workshop on Modelling of Metal Powder Forming Processes, Grenoble, France, 21-23 July, pp.149-157.

Wu, C.-Y., Cocks, A.C.F., Gillia, O.T. and Thompson, D.A., 2003. Experimental and numerical investigations of powder transfer. Powder Technology., Vol. 138, pp. 216-228.

Wu, C.-Y., Ruddy, O.M., Bentham, A.C., Hancock, B.C., Best, S.M. and Elliott J.A., 2005. Modelling the mechanical behaviour of pharmaceutical powders during compaction. Powder Technology, Vol. 152, pp. 107-117.

Wu, C.-Y. and Cocks, A.C.F., 2006. Numerical and experimental investigations of the flow of powder into a confined space Mechanics of Materials, Vol. 38, Issue 4, pp. 304-324.
Wu, C.-Y, Hancock B.C., Mills A., Bentham, A.C., Best, S.M. and Elliott, J.A., 2007. Numerical and experimental investigation of capping mechanisms during pharmaceutical tablet compaction. Powder Technology, In Press, Corrected Proof, Available online 14 December 2006,

Zeuch, D.H., Grazier, J.M., Arguello, J.G. and Ewsuk, K.G., 2001. Mechanical properties and shear failure surfaces for two alumina powders in triaxial compression. Journal of Material Science, Vol. 36, pp.2911-2924.

\section{Author's short biography}

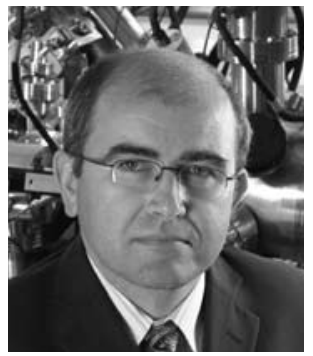

\section{Dr. Csaba Sinka}

Dr. Csaba Sinka was appointed in 2006 to a Lectureship in Mechanics of Materials in the Department of Engineering at the University of Leicester. Previously he was a Research Fellow at Merck Sharp and Dohme where he worked in formulation design and process development of pharmaceutical tablets.

He has as a background in mechanical, mineral and process engineering and has worked in academic and industrial research in the UK and the US. His main research interest is in powder technology and particulate engineering and has developed experimental and numerical modelling techniques to address practical problems involving powder flow and compaction with applications to powder metallurgy, ceramics, hard metals and the pharmaceutical industry.

His current research is in the following 3 areas: the flow of powders in constrained cavities (where air pressure build-up plays an important role) with application to industrial die fill; multi-scale modelling of particle-particle interactions; and modelling the biodegradation of polymeric materials with application to orthopaedic fixation devices and controlled release tablets. 